\title{
Administration of pioglitazone alone or with alogliptin delays diabetes onset in UCD-T2DM rats
}

\author{
Bethany P Cummings, Ahmed Bettaieb ${ }^{2}$, James L Graham ${ }^{1,2}$, Kimber Stanhope ${ }^{1,2}$, \\ Fawaz G Haj ${ }^{2,3}$ and Peter J Havel ${ }^{1,2}$ \\ Department of Biomedical Sciences, College of Veterinary Medicine, Cornell University, \\ T7 022A Veterinary Research Tower (Box 17), Ithaca, New York 14850, USA \\ ${ }^{1}$ Department of Molecular Biosciences, School of Veterinary Medicine and ${ }^{2}$ Department of Nutrition, \\ University of California Davis, Davis, California, USA \\ ${ }^{3}$ Department of Internal Medicine, University of California, Davis, Sacramento, California, USA
}

\author{
Correspondence \\ should be addressed \\ to B P Cummings \\ Email \\ bpc68@cornell.edu
}

\begin{abstract}
There is a need to identify strategies for type 2 diabetes prevention. Therefore, we investigated the efficacy of pioglitazone and alogliptin alone and in combination to prevent type 2 diabetes onset in UCD-T2DM rats, a model of polygenic obese type 2 diabetes. At 2 months of age, rats were divided into four groups: control, alogliptin ( $20 \mathrm{mg} / \mathrm{kg}$ per day), pioglitazone ( $2.5 \mathrm{mg} / \mathrm{kg}$ per day), and alogliptin + pioglitazone. Non-fasting blood glucose was measured weekly to determine diabetes onset. Pioglitazone alone and in combination with alogliptin lead to a 5-month delay in diabetes onset despite promoting increased food intake and body weight (BW). Alogliptin alone did not delay diabetes onset or affect food intake or BW relative to controls. Fasting plasma glucose, insulin, and lipid concentrations were lower and adiponectin concentrations were threefold higher in groups treated with pioglitazone. All treatment groups demonstrated improvements in glucose tolerance and insulin secretion during an oral glucose tolerance test with an additive improvement observed with alogliptin + pioglitazone. Islet histology revealed an improvement of islet morphology in all treatment groups compared with control. Pioglitazone treatment also resulted in increased expression of markers of mitochondrial biogenesis in brown adipose tissue and white adipose tissue, with mild elevations observed in animals treated with alogliptin alone. Pioglitazone markedly delays the onset of type 2 diabetes in UCD-T2DM rats through improvements of glucose tolerance, insulin sensitivity, islet function, and markers of adipose mitochondrial biogenesis; however, addition of alogliptin at a dose of $20 \mathrm{mg} / \mathrm{kg}$ per day to pioglitazone treatment does not enhance the prevention/delay of diabetes onset.
\end{abstract}
Key Words
- pioglitazone
- type 2 diabetes
- alogliptin
- islet

Journal of Endocrinology (2014) 221, 133-144

\section{Introduction}

The prevalence of type 2 diabetes is steadily rising with approximately one in ten adults affected in industrialized countries (Danaei et al. 2011), necessitating the advent of more effective therapeutic strategies for the prevention and treatment of type 2 diabetes (DeFronzo \& AbdulGhani 2011). While the pharmacotherapeutic options for the treatment of type 2 diabetes are expanding and improving, patients suffering from type 2 diabetes 
continue to experience a higher risk of developing comorbidities such as cardiovascular disease, cancer, and renal failure (Ritz et al. 1999, Czyzyk \& Szczepanik 2000, Mazzone et al. 2008). Delaying the onset of frank type 2 diabetes will likely delay the development of these longterm complications. The development of multimodal therapies may be more effective in the treatment and prevention of type 2 diabetes and its co-morbidities than monotherapy. Two common drug targets for the treatment of type 2 diabetes are peroxisome proliferator receptor $\gamma$ (PPAR $\gamma$ ) and glucagon-like peptide 1 (GLP1).

$\operatorname{PPAR} \gamma$ is a nuclear receptor that is highly expressed in adipose tissue and macrophages and acts to upregulate the expression of factors involved in adipocyte differentiation and triglyceride storage (Ferre 2004). PPAR $\gamma$ is targeted by the thiazolidinedione (TZD) class of drugs (Nolte et al. 1998, Rosen \& Spiegelman 2001, Semple et al. 2006). Agonism of PPAR $\gamma$ by TZDs leads to decreases in circulating glucose and lipid concentrations and marked improvements of insulin sensitivity in type 2 diabetic patients, making TZDs commonly prescribed for the treatment of type 2 diabetes (Olefsky 2000, Sharma \& Staels 2007, Nissen et al. 2008). Pioglitazone is a member of the TZD family and is commonly used in the treatment of type 2 diabetes due to its potent glucose-lowering and insulin-sensitizing effects (Olefsky 2000, Semple et al. 2006). Furthermore, a recent clinical study demonstrated that pioglitazone treatment of patients with impaired glucose tolerance reduced the risk of conversion to type 2 diabetes by $72 \%$, demonstrating that pioglitazone alone is an effective strategy for delaying type 2 diabetes onset (DeFronzo et al. 2011).

GLP1 has become a well-established drug target for the treatment of type 2 diabetes (Drucker \& Nauck 2006). We have previously reported that the GLP1 receptor agonist, liraglutide, substantially delays the onset of diabetes in the UCD-T2DM rat model (Cummings et al. 2010). Endogenous GLP1 has a short half-life in the circulation of $<2 \mathrm{~min}$ due to rapid degradation by DPP-IV (Baggio \& Drucker 2007). Therefore, DPP-IV inhibitors, such as aloglipitin, have been developed in order to prolong the activity of endogenous GLP1 (Feng et al. 2007, Thomas et al. 2008). As an incretin hormone, GLP1 potentiates glucosestimulated insulin secretion (Baggio \& Drucker 2007). Furthermore, GLP1 has been shown to lower glucagon secretion, preserve $\beta$-cell mass, and improve insulin sensitivity, independent of its effects on insulin secretion (Brubaker \& Drucker 2004, Baggio \& Drucker 2007). Alogliptin has proven effective for improving glucose and lipid homeostasis in rodent models of type 2 diabetes and in type 2 diabetic patients (DeFronzo et al. 2008, Moritoh et al. 2008, Pratley et al. 2009a, Zhang et al. 2011).

These complementary mechanisms of action suggest that alogliptin and pioglitazone given in combination may act synergistically to improve glucose and lipid homeostasis. Indeed, studies on rodents and clinical studies on type 2 diabetic patients report that addition of alogliptin to pioglitazone monotherapy results in additive effects to lower blood glucose concentrations (Moritoh et al. 2009, Pratley et al. 2009b, Rosenstock et al. 2010, DeFronzo et al . 2012). However, the efficacy of alogliptin alone and in combination with pioglitazone to delay the onset of type 2 diabetes has not been previously investigated. Therefore, we used the UCD-T2DM rat model to test the hypothesis that pioglitazone and alogliptin in combination would be more effective in delaying type 2 diabetes onset in prediabetic UCD-T2DM rats than either treatment alone. The UCD-T2DM rat model develops adult-onset polygenic obesity, insulin resistance, and subsequent type 2 diabetes (Cummings et al. 2008).

\section{Materials and methods}

\section{Diets and animals}

Male UCD-T2DM rats were individually housed in wire cages in the Department of Nutrition animal facility at the University of California, Davis, and maintained on a $14 \mathrm{~h}$ light:10 h darkness cycle. Starting at 2 months of age, male siblings were divided into four groups: control, alogliptin (20 mg/kg per day), pioglitazone ( $2.5 \mathrm{mg} / \mathrm{kg}$ per day), and alogliptin + pioglitazone ( $n=32$ per group). Groups were matched for weight at the initiation of treatment and all animals received ground chow (no. 5012, Ralston Purina, Belmont, CA, USA). Drug compounds were mixed into the ground chow such that animals received the appropriate daily dose throughout the study. Food intake and body weight (BW) were measured three times a week. Non-fasting blood glucose was monitored every week with a glucose meter (One-Touch Ultra, LifeScan, Milpitas, CA, USA) at 1300-1400 h using a lancet to collect a drop of blood from the tail. Diabetes onset was defined as a non-fasted blood glucose value above $11.1 \mathrm{mmol} / \mathrm{l}$ on 2 consecutive weeks (Cummings et al. 2008). One half of the animals in each group $(n=16)$ were killed for tissue collection at 6.5 months of age (short-term study), and the remaining half ( $n=16)$ continued treatment up to 1 year of age (longterm study). Monthly blood samples were collected up to 8 months of age. An oral glucose tolerance test (OGTT; $1 \mathrm{~g} / \mathrm{kg}$ BW gavage with dextrose) was conducted after

Published by Bioscientifica Ltd. 
3.5 months of treatment. The experimental protocols were approved by the UC Davis Institutional Animal Care and Use Committee. Standard methods for plasma and tissue analyses are described in detail in the Supplemental Materials and Methods, see section on supplementary data given at the end of this article.

\section{Statistics and data analysis}

Data are presented as mean \pm s.E.M. Statistical analyses were performed using GraphPad Prism 4.00 for Windows, GraphPad Software (San Diego, CA, USA). All time course data were compared by two-factor repeated measures ANOVA followed by post hoc analysis with Bonferroni's multiple comparison test. Incidence data were analyzed by log-rank testing of Kaplan-Meier survival curves. Age of onset, OGTT incremental area under the curve (AUC), tissue weights, and tissue measurements were analyzed by Student's $t$-test. Differences were considered significant at $P<0.05$.

\section{Results}

\section{Pioglitazone delays type 2 diabetes onset alone and in combination with alogliptin}

Compared with control animals, pioglitazone administration alone and in combination with alogliptin delayed type 2 diabetes onset by $\sim 5$ months (Fig. 1A).
In the long-term study, the average age of diabetes onset was $6.0 \pm 0.6,5.8 \pm 0.5,11.0 \pm 0.6$, and $11.1 \pm 0.6$ months in control, alogliptin-, pioglitazone-, and alogliptin + pioglitazone-treated animals respectively $(P<0.001)$. In the long-term study, all animals in the control and alogliptin-treated groups developed diabetes whereas only $43.8 \%(7 / 16)$ of animals in the pioglitazone and $37.5 \%(6 / 16)$ of animals in the alogliptin + pioglitazonetreated groups developed diabetes. When data from animals up to 6 months of age in the long- and shortterm studies were combined, the incidence of diabetes up to 6 months of age was $0 \%$ for both the pioglitazone- and alogliptin + pioglitazone-treated groups, whereas diabetes incidence was 53.1\% (17/32) and 59.4\% (19/32) in the control and alogliptin-treated groups respectively (Fig. 1B). The delay of diabetes onset in animals treated with pioglitazone alone and in combination with alogliptin was reflected in lower fasting and fed circulating glucose concentrations and lower HbA1c concentrations at 5 and 6 months of age compared with the control group $(P<0.001$; Fig. 1C, D and E).

Pioglitazone alone and in combination with alogliptin led to a marked delay in diabetes onset despite its well-known effects to increase food intake, BW, and adiposity. Pioglitazone alone and in combination with alogliptin led to a $\sim 10 \%$ increase in food intake between 2 and 4.5 months of age and increased BW throughout the first 6 months of study $(P<0.01$; Fig. $2 \mathrm{~A}, \mathrm{~B}$ and $\mathrm{C})$.
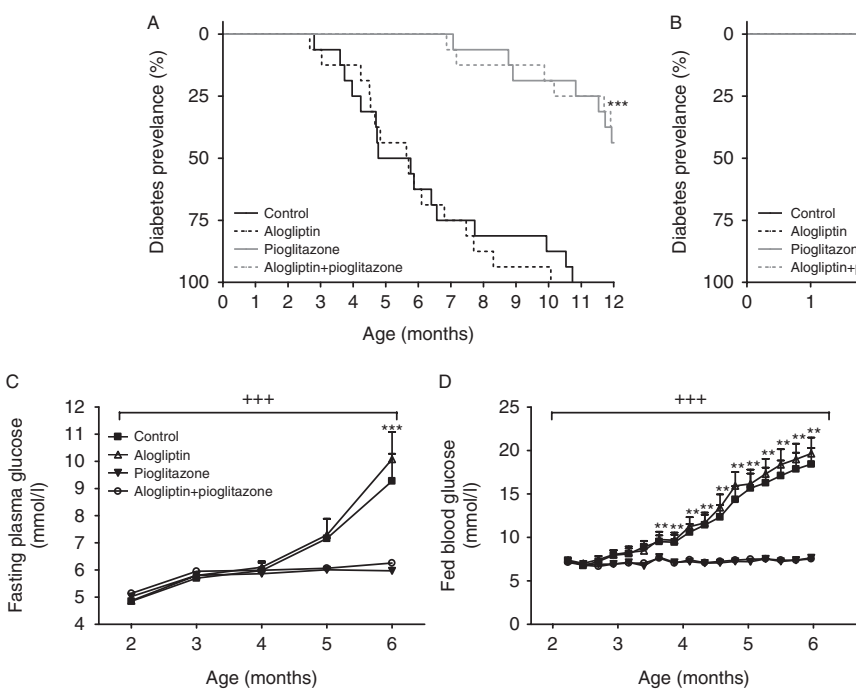

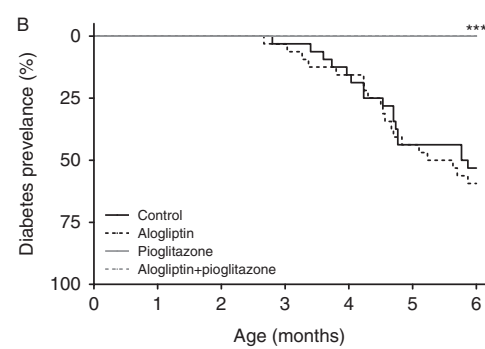

E

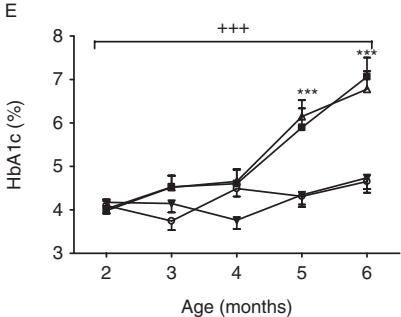

\section{Figure 1}

Kaplan-Meier analysis of diabetes incidence in control, alogliptin-, pioglitazone-, and alogliptin + pioglitazone-treated animals up to 12 months ( $n=16$ per group) (A) and 6 months ( $n=32$ per group) (B) of age. $* * * P<0.0001$ compared with control and alogliptin by log-rank test.
Fasting plasma glucose (C), non-fasting blood glucose (D), and fasting $\mathrm{HbA} 1 \mathrm{C}(\mathrm{E}) .{ }^{++}{ }^{+} P<0.001$ by two-factor repeated measures ANOVA, $\star * * P<0.001$, and $* * P<0.01$ compared with control and alogliptin by Bonferroni's posttest. http://joe.endocrinology-journals.org DOI: 10.1530/JOE-13-0601
(C) 2014 Society for Endocrinology Printed in Great Britain 

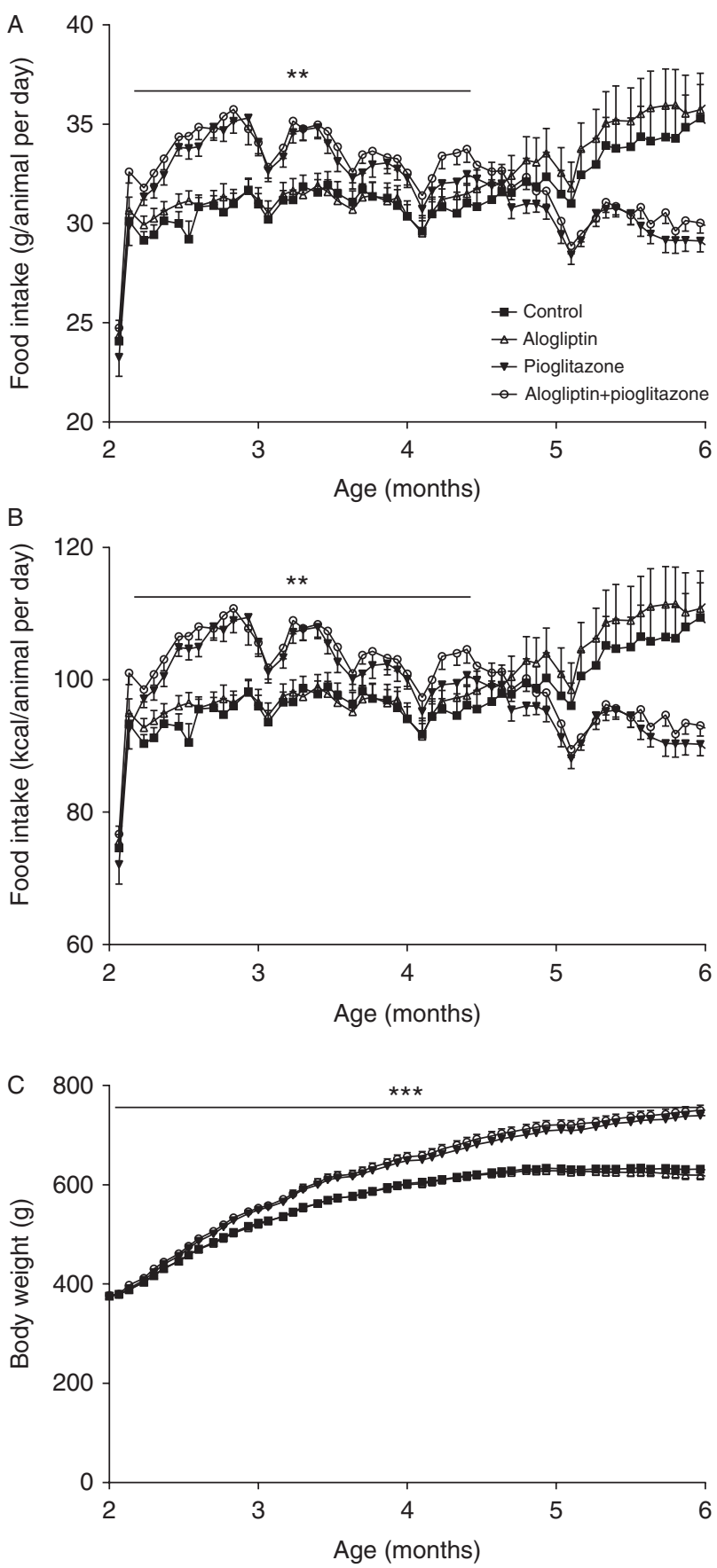

Figure 2

Food intake (g/animal per day) (A), food intake (kcal/animal per day) (B), and body weight (C). $* * * P<0.001$ and $* * P<0.01$ by two-factor repeated measures ANOVA and Bonferroni's posttest compared with control and alogliptin, $n=32$ per group.

Alogliptin treatment did not affect food intake or BW compared with the control group. Food intake increased in the control and alogliptin-treated animals starting at 5 months of age because diabetes prevalence in these groups had increased resulting in diabetic hyperphagia, as previously reported (Cummings et al. 2008). The epididymal, retroperitoneal, subcutaneous, and total white adipose tissue (WAT) weights were significantly elevated in pioglitazone and alogliptin + pioglitazone groups compared with the control group $(P<0.001)$; however, mesenteric adipose depot weight did not differ between groups (Table 1).

\section{Pioglitazone alone and in combination with alogliptin reduces circulating insulin and lipid concentrations}

Similar to previous studies demonstrating that pioglitazone markedly improves insulin sensitivity (Ferre 2004, Kim \& Ahn 2004), pioglitazone alone and in combination with alogliptin significantly reduced fasting plasma insulin concentrations (Fig. 3A). Insulin concentrations began to fall in control and alogliptin-treated groups at 5 and 6 months of age because a large proportion of these animals had developed diabetes and were undergoing pancreatic $\beta$-cell decompensation with the progression of their diabetes, as previously described (Cummings et al. 2008). Furthermore, pioglitazone alone and in combination with alogliptin resulted in a threefold increase in circulating adiponectin concentrations (Fig. 3B) with corresponding increases in AMPK phosphorylation $\left(\mathrm{Thr}^{172}\right)$ in subcutaneous WAT and brown adipose tissue (BAT) (Fig. 3C). Interestingly, animals treated with alogliptin alone exhibited a significant increase in AMPK phosphorylation in both subcutaneous BAT and WAT compared with controls; however, this enhancement of AMPK signaling was significantly lower than that seen in pioglitazone-treated animals $(P<0.01)$. Pioglitazone treatment resulted in a twofold increase in fasting plasma leptin concentrations compared with controls, which was likely due to the expansion of adiposity (Fig. 3D). Interestingly, pioglitazone and alogliptin in combination significantly reduced fasting plasma glucagon concentrations after 2 and 3 months of treatment compared with controls and compared with pioglitazone and alogliptin alone (Fig. 3E).

Pioglitazone treatment alone and in combination with alogliptin resulted in improvements of lipid metabolism including marked reductions of fasting plasma free fatty acid (FFA), cholesterol, and triglyceride (TG) concentrations $(P<0.001$; Fig. 4A, B and $\mathrm{C})$. Enzymes involved in the regulation of fatty acid oxidation and lipogenesis were measured in subcutaneous WAT and BAT by immunoblotting in order to perform an initial investigation of the molecular basis for the observed improvement of circulating lipid concentrations with pioglitazone treatment. Phosphorylation and inactivation of acetyl-CoA carboxylase

Published by Bioscientifica Ltd. 
Table 1 Tissue weights, tissue TG content, and pancreatic insulin and glucagon content. Values are mean \pm s.E.M. $(n=16)$

\begin{tabular}{l}
\hline \\
Epididymal fat depot $(\mathrm{g})$ \\
Retroperitoneal fat depot $(\mathrm{g})$ \\
Subcutaneous depot $(\mathrm{g})$ \\
Mesenteric depot $(\mathrm{g})$ \\
Total white adipose tissue $(\mathrm{g})$ \\
Heart $(\mathrm{g})$ \\
Kidney $(\mathrm{g})$ \\
Liver $(\mathrm{g})$ \\
Liver TG ( $\mu \mathrm{mol} / \mathrm{g}$ tissue) \\
Skeletal muscle TG ( $\mu \mathrm{mol} / \mathrm{g}$ tissue) \\
Pancreas insulin ( $\mu \mathrm{mol} / \mathrm{g}$ tissue) \\
Pancreas glucagon (pmol/g tissue)
\end{tabular}

\begin{tabular}{r}
\multicolumn{1}{c}{ Control } \\
\hline $8.1 \pm 0.4$ \\
$12.9 \pm 0.6$ \\
$45.8 \pm 2.8$ \\
$7.2 \pm 0.5$ \\
$74.8 \pm 4.0$ \\
$1.6 \pm 0.1$ \\
$2.0 \pm 0.1$ \\
$21.1 \pm 0.5$ \\
$25.2 \pm 3.2$ \\
$4.2 \pm 0.7$ \\
$3.4 \pm 0.9$ \\
$95 \pm 17$
\end{tabular}

Alogliptin
$7.0 \pm 0.4^{*}$
$10.9 \pm 0.8^{*}$
$40.1 \pm 3.9$
$5.7 \pm 0.6$
$64.5 \pm 5.6$
$1.5 \pm 0.1$
$2.0 \pm 0.1$
$20.5 \pm 0.4$
$19.6 \pm 4.0$
$3.0 \pm 0.5$
$2.7 \pm 0.8$
$62 \pm 8^{*}$

\begin{tabular}{c} 
Pioglitazone \\
\hline $10.9 \pm 0.6^{\ddagger}$ \\
$22.8 \pm 1.4^{\ddagger}$ \\
$85.1 \pm 6.5^{\ddagger}$ \\
$7.8 \pm 0.4$ \\
$129.4 \pm 8.6^{\ddagger}$ \\
$1.7 \pm 0.1^{*}$ \\
$1.9 \pm 0.1^{*}$ \\
$17.8 \pm 0.3^{\ddagger}$ \\
$21.0 \pm 2.0$ \\
$7.6 \pm 0.9^{\dagger}$ \\
$4.9 \pm 0.5$ \\
$72 \pm 11$
\end{tabular}

Alogliptin + Pioglitazone

$12.0 \pm 0.7^{\ddagger}$

$23.3 \pm 1.2^{\ddagger}$

$94.7 \pm 5.0^{\ddagger}$

$8.1 \pm 0.4$

$141.1 \pm 7.2^{\ddagger}$

$1.7 \pm 0.1 *$

$1.9 \pm 0.1$

$18.8 \pm 0.4^{\ddagger}$

$19.8 \pm 1.9$

$7.4 \pm 0.7^{\dagger}$

$5.3 \pm 0.5^{*}$

$60 \pm 11 *$

${ }^{*} P<0.05,{ }^{\dagger} P<0.01$, and ${ }^{\ddagger} P<0.001$ compared with control by one-factor ANOVA.

$\left(\right.$ ACC Ser ${ }^{79}$ ) was elevated in pioglitazone-treated animals in both BAT and WAT compared with controls $(P<0.05)$, suggesting an enhancement of fatty acid oxidation (Fig. 4D and E). Inactive phosphorylated ACC ( $\operatorname{Ser}^{79}$ ) was also significantly elevated in alogliptin-treated animals in BAT only $(P<0.05$; Fig. 4D). Similar to a previous report in humans (Ranganathan et al. 2006), fatty acid synthase (FAS) protein expression was elevated with pioglitazone treatment in both BAT and WAT, suggesting an enhancement of lipogenesis in adipose tissue. Liver TG content did not differ significantly between groups (Table 1); however, when diabetic animals were excluded from the control group, liver TG concentrations were significantly elevated in control animals (control $=29.7 \pm 3.8 \mu \mathrm{mol} \mathrm{TG} / \mathrm{g}$ tissue) compared with pioglitazone and alogliptin + pioglitazone $(P<0.05)$. By contrast, skeletal muscle TG concentrations were significantly elevated in pioglitazone- and alogliptin + pioglitazone-treated animals (Table 1). This difference persisted when diabetic animals were excluded from the analysis.

\section{Pioglitazone and alogliptin improve glucose tolerance and insulin secretion}

Based on the significant improvements of fasting plasma glucose concentrations with pioglitazone treatment, we investigated potential improvements of glucose tolerance
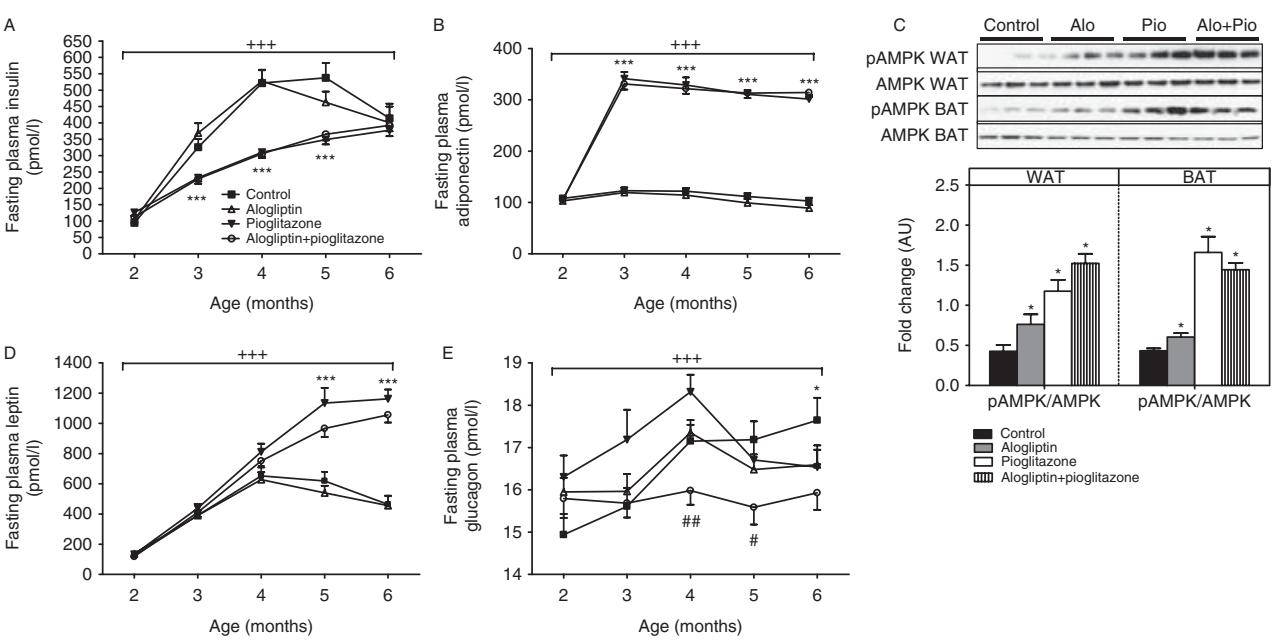

Figure 3

Fasting plasma insulin (A), adiponectin (B), leptin (D), and glucagon (E) concentrations. ${ }^{++} P<0.001$ by two-factor repeated measures ANOVA, ${ }^{* * *} P<0.001$ compared with control and alogliptin, ${ }^{\# \#} P<0.01$, and ${ }^{\#} P<0.05$ for alogliptin + pioglitazone compared with control, alogliptin, and pioglitazone by Bonferroni's posttest, $n=32$ per group. Representative immunoblots for AMPK and pAMPK $\left(\mathrm{Thr}^{172}\right)$ in subcutaneous white adipose tissue (WAT) and brown adipose tissue (BAT). All blots were scanned and quantified using FluorChem 9900. Results were quantified in densitromic units and expressed relative to AMPK (C). ${ }^{*} P<0.05$ compared with control by Student's $t$-test, $n=16$ per group. 

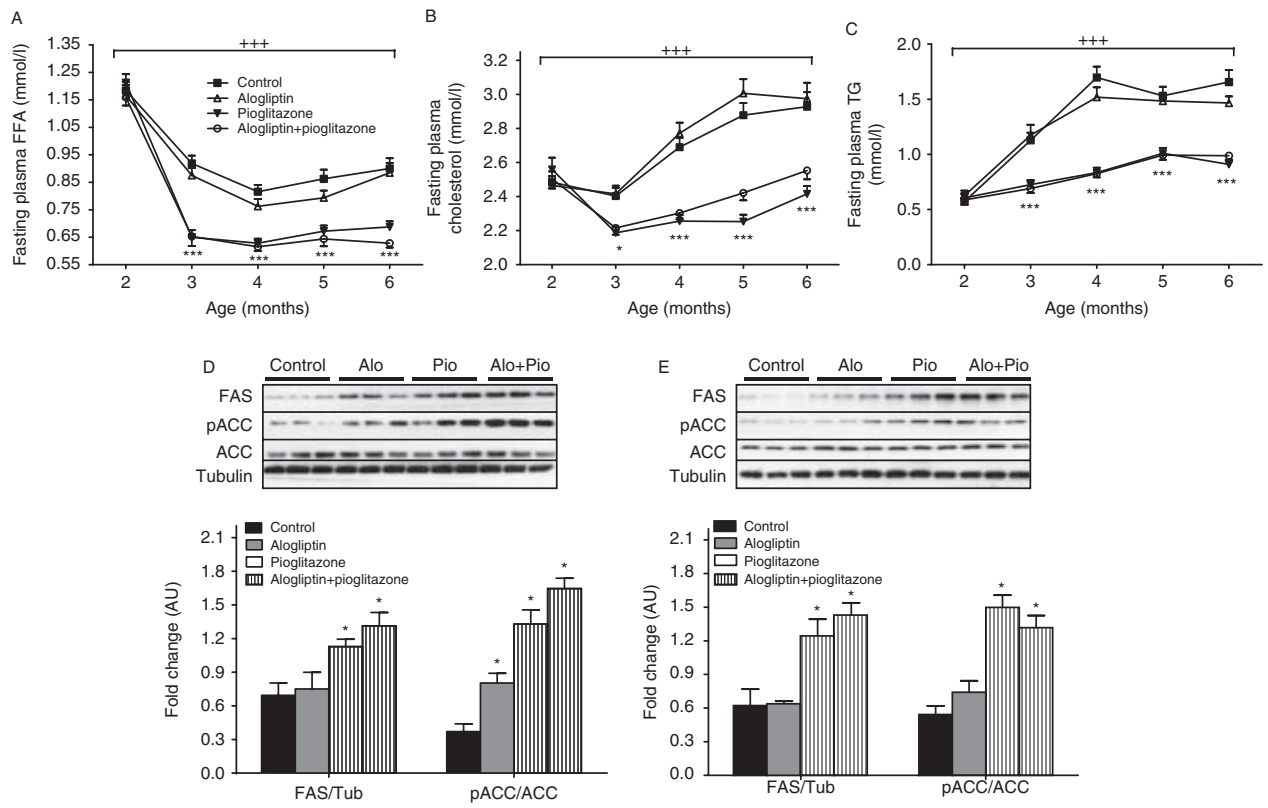

\section{Figure 4}

Fasting plasma FFA (A), cholesterol (B), and TG (C) concentrations.

${ }^{+++} P<0.001$ by two-factor repeated measures ANOVA, $* * * P<0.001$, and

$* P<0.05$ compared with control and aloglitpin by Bonferroni's posttest,

$n=32$ per group. Representative immunoblots for FAS, pACC $\left(\mathrm{Ser}^{79}\right)$, ACC

and glucose-stimulated insulin secretion by OGTT (at 5.5 months of age). Glucose excursions during the OGTT were significantly reduced in all treatment groups compared with controls. However, the glucose AUC was significantly lower in animals treated with pioglitazone and alogliptin in combination compared with either pioglitazone or alogliptin alone, suggesting that pioglitazone and alogliptin act in an additive manner to improve glucose tolerance (Fig. 5A; glucose AUC: control $=549 \pm 30$, alogliptin $=468 \pm 34$, pioglitazone $=458 \pm 28$, and alogliptin + pioglitazone $=376 \pm$ $24 \mathrm{mmol} / 1 \times 120 \mathrm{~min} ; P<0.05$ ).

While fasting plasma insulin concentrations at baseline were significantly lower in animals treated with pioglitazone alone and in combination with alogliptin, the insulin AUC was significantly higher in animals treated with pioglitazone alone and in combination with alogliptin compared with control animals (insulin AUC: control $=22039 \pm 3506$, alogliptin $=19268 \pm 3075$, pioglitazone $=33946 \pm 2484$, and alogliptin + pioglitazone $=$ $34857 \pm 2510 \mathrm{pmol} / \mathrm{l} \times 120 \mathrm{~min} ; P<0.05)$. However, insulin concentrations were significantly lower in pioglitazone- and pioglitazone + alogliptin-treated animals at multiple time points and all three treatment groups demonstrated a significantly greater percent increase in circulating insulin concentrations from baseline to peak and tubulin. All blots were scanned and quantified using FluorChem 9900. Results were quantified in densitromic units and expressed relative to the protein of interest or to tubulin for FAS in subcutaneous BAT (D) and WAT (E). ${ }^{*} P<0.05$ compared with control by Student's $t$-test, $n=16$ per group.

values (\% change from baseline: control $=118 \pm 14 \%$, alogliptin $=206 \pm 35 \%$, pioglitazone $=319 \pm 49 \%$, and alogliptin + pioglitazone $=458 \pm 91 \% ; P<0.05$; Fig. 5B).

GLP1 concentrations were measured during the OGTT in order to identify potential influences of chronic alogliptin and pioglitazone treatment on endogenous postprandial GLP1 secretion. Surprisingly, the GLP1 AUC was significantly lower in animals treated with alogliptin alone and in combination with pioglitazone (GLP1 AUC: control $=130 \pm 13$, alogliptin $=93 \pm 10$, pioglitazone $=$ $131 \pm 13$, and alogliptin + pioglitazone $=101 \pm 11 \mathrm{pmol} / \mathrm{l} \times$ $120 \mathrm{~min} ; P<0.05$; Fig. 5C). In order to ensure that alogliptin treatment was prolonging the half-life of endogenously secreted active GLP1, the acute effects of alogliptin administration on plasma active GLP1 concentrations was measured in a separate group of male UCD-T2DM rats. Rats were fasted overnight and the next morning they received a gavage of dextrose $(1 \mathrm{~g} / \mathrm{kg}$ dextrose) with or without alogliptin $(1 \mathrm{mg} / \mathrm{kg} \mathrm{BW})$ and active GLP1 was measured. Animals receiving alogliptin exhibited a twofold higher active GLP1 AUC than control animals, demonstrating that UCD-T2DM rats exhibit appropriate postprandial increases in active GLP1 (active GLP1 AUC: control $=148 \pm 19 \mathrm{pmol} / 1 \times 60 \mathrm{~min}$ and alogliptin $=317 \pm 90 \mathrm{pmol} / 1 \times 60 \mathrm{~min} ; P<0.05$; Fig. 5D).

Published by Bioscientifica Ltd 

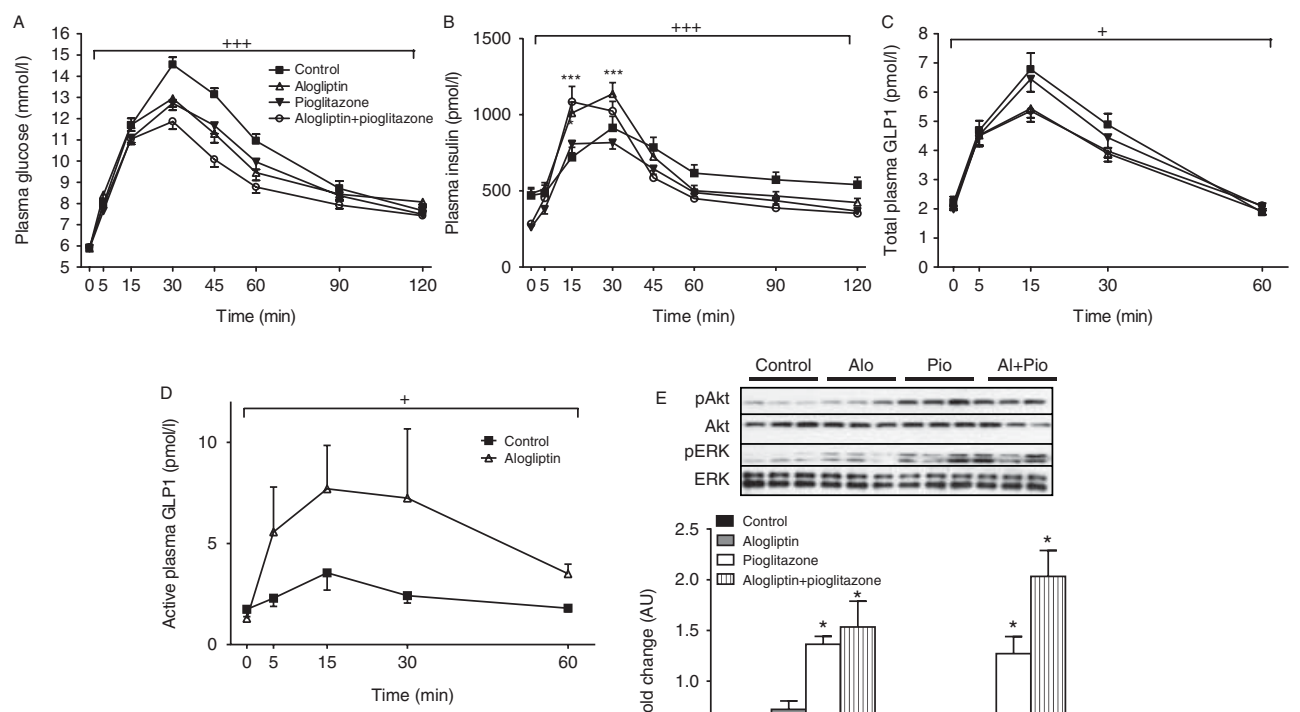

Figure 5

Circulating glucose (A), insulin (B), and total GLP1 (C) concentrations during an OGTT at 3.5 months after the initiation of treatment. Animals were fasted overnight and received a $1 \mathrm{~g} / \mathrm{kg}$ gavage of a $50 \%$ dextrose solution. ${ }^{++} P<0.001$ for all groups compared with control, and ${ }^{+} P<0.05$ for alogliptin and alogliptin + pioglitazone compared with control by onefactor ANOVA of the AUC. $* * * P<0.05$ by one-factor ANOVA of the percent increase in insulin from baseline to peak values compared with the control group, $n=32$ per group. Plasma active GLP1 in a separate group of male UCD-T2DM rats $(n=4)$. Rats were fasted overnight and then received a

In order to investigate the molecular basis for enhanced insulin sensitivity in pioglitazone-treated animals, we analyzed downstream components of insulin signaling pathways in subcutaneous WAT of fasted animals at study termination (6.5 months of age). Akt $\left(\mathrm{Ser}^{473}\right)$ and ERK1/2 $\left(\mathrm{Thr}^{202} / \mathrm{Tyr}^{204}\right.$ ) phosphorylation, normalized to their protein expression, were two- to threefold higher in WAT in animals treated with pioglitazone compared with controls $(P<0.05$; Fig. $5 \mathrm{E})$. Alogliptin did not significantly affect Akt or ERK1/2 phosphorylation.

\section{Pioglitazone and alogliptin treatment preserve islet morphology}

In order to investigate the potential effects of pioglitazone and alogliptin on $\beta$-cell mass and islet morphology, immunostaining for pancreatic insulin and glucagon was performed in a subset of animals killed at 6.5 months of age. Cohorts in which none of the animals had developed diabetes were specifically selected for immunohistochemistry in order to avoid confounding by the presence gavage of dextrose $(1 \mathrm{~g} / \mathrm{kg})$ with or without alogliptin mixed in with the dextrose to provide a dose of $1 \mathrm{mg}$ alogliptin/kg body weight. ${ }^{+} P<0.05$ compared with control by Student's $t$-test of the AUC (D). Representative immunoblots for pAkt $\left(\mathrm{Ser}^{473}\right)$, Akt, pERK $\left(\mathrm{Thr}^{202} / \mathrm{Tyr}^{204}\right)$, and ERK in white adipose tissue. All blots were scanned and quantified using FluorChem 9900. Results were quantified in densitromic units and expressed relative to the protein of interest $(E)$. ${ }^{*} P<0.05$ compared with control by Student's $t$ test, $n=16$ per group.

of diabetes. In general, islets from all the three treatment groups appeared smaller with better preservation of islet architecture than islets from control animals (Fig. 6A, B, C and $D)$. Quantification of $\beta$-cell mass, average islet size, and average number of islets per section revealed that control animals exhibited greater $\beta$-cell mass with larger islets and fewer islets per section compared with all the three treatment groups $(P<0.05$; Fig. $6 \mathrm{E}, \mathrm{F}$ and $\mathrm{G})$.

As a confirmation of the immunohistochemistry data set, insulin and glucagon were extracted from whole pancreas samples as an index of $\beta$-cell and $\alpha$-cell mass. When all animals were included in the analysis, pancreatic insulin content was significantly higher in pioglitazoneand pioglitazone + alogliptin-treated groups compared with the control and alogliptin treatment groups (Table 1). However, consistent with the islet immunohistochemistry results, when diabetic animals were excluded from the analysis, pancreatic insulin content was significantly higher in the control animals compared with pioglitazone- and pioglitazone + alogliptin-treated groups (excluding diabetic animals: $\operatorname{control}=7.3 \pm 0.9 \mu \mathrm{mol} / \mathrm{g}$ pancreas; $P<0.05$ ).

Published by Bioscientifica Ltd. 

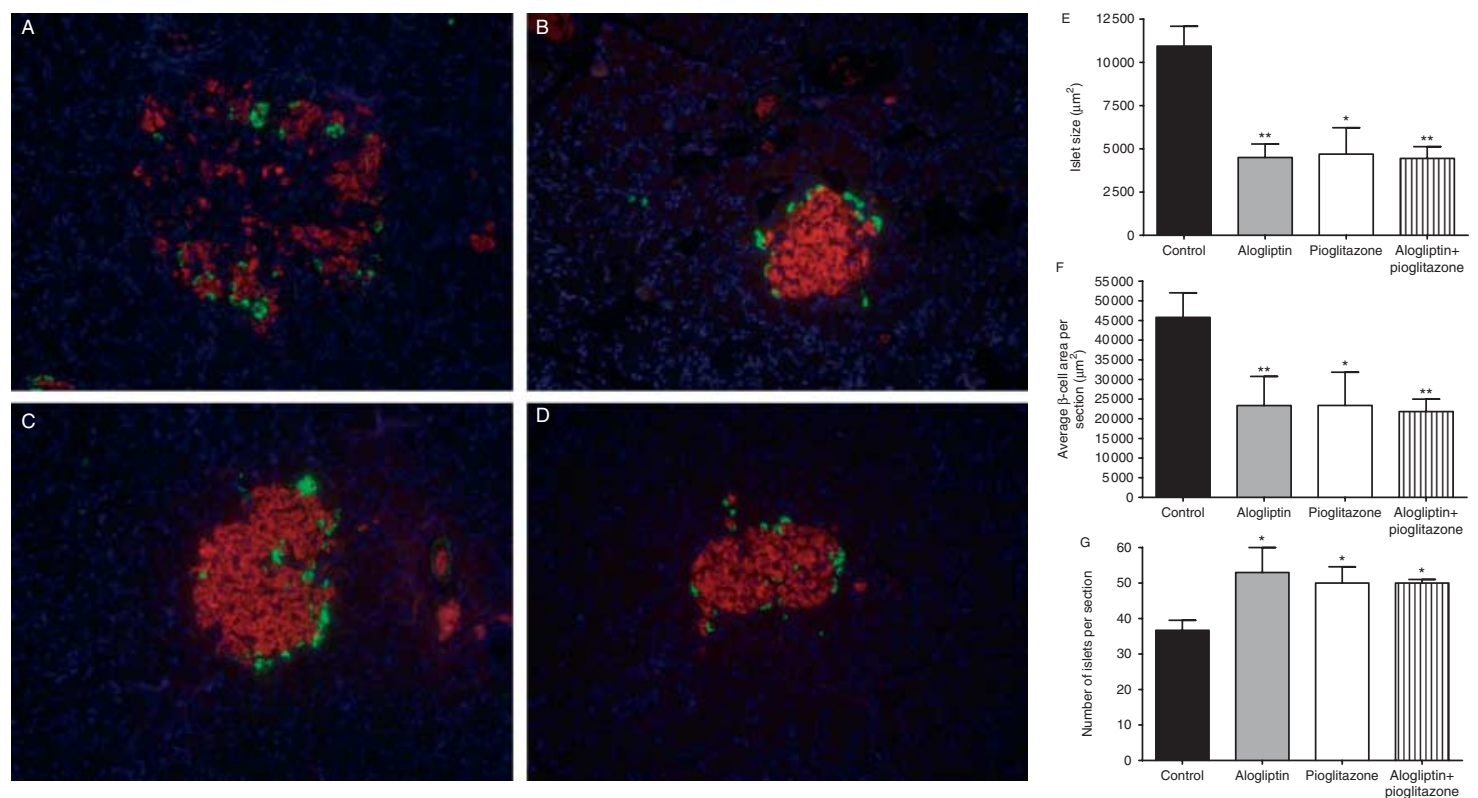

\section{Figure 6}

Representative images from pancreas sections from prediabetic control, alogliptin-, pioglitazone-, and alogliptin + pioglitazone-treated animals. Insulin immunostaining is in red, glucagon is in green, and nuclei are stained blue with DAPI. Merged insulin, glucagon, and DAPI staining in control (A), alogliptin (B), pioglitazone (C), and alogliptin + pioglitazone (D).

Interestingly, pancreatic glucagon content was significantly lower in animals treated with alogliptin alone and in combination with pioglitazone compared with controls $(P<0.05)$.

\section{Pioglitazone increases markers of mitochondrial biogenesis}

In order to determine whether changes in adipose tissue mitochondrial biogenesis may be contributing to the improvements of glucose tolerance with pioglitazone and alogliptin treatment, markers of energy uncoupling and mitochondrial biogenesis were measured in subcutaneous WAT and BAT by RT-PCR. All the three treatment groups exhibited significant increases in uncoupling protein 1 (UCP1), peroxisome proliferator-activated receptor $\gamma$ coactivator $1 \alpha(\mathrm{PGC} 1 \alpha)$, and cytochrome $c$ oxidase subunit $8 \mathrm{~b}$ (Cox8b) mRNA in BAT and WAT (Fig. 7A and B). UCP1 is an inner mitochondrial membrane transporter of FFAs that allows for the dissipation of energy as heat (Cardoso et al. 2010). PGC1 $\alpha$ is a key transcriptional regulator of oxidative metabolism and Cox $8 b$ is a gene involved in mitochondrial oxidative phosphorylation that is upregulated by PGC1 $\alpha$. Increases in markers of mitochondrial biogenesis were more pronounced in pioglitazone-treated animals than in
Quantification of average islet size $(E)$, average $\beta$-cell area per section $(F)$, and average number of islets per section $(G) ; * P<0.01$ and $* P<0.05$ compared with control by Student's $t$-test, $n=3$ per group. Ten sections per pancreas used for quantification.

animals receiving alogliptin alone $(P<0.05)$. Addition of alogliptin to pioglitazone treatment did not produce an additional elevation in UCP1 or PGC1 $\alpha$ expression. However, alogliptin and pioglitazone in combination resulted in higher Cox $8 b$ mRNA levels than either alogliptin or pioglitazone alone $(P<0.05)$.

\section{Discussion}

Results from previous studies have suggested that pioglitazone and alogliptin in combination may act synergistically to provide greater glucose-lowering effects than either agent alone (DeFronzo et al. 2008, Pratley et al. 2009a, Rosenstock et al. 2009, Kaku et al. 2011, Eliasson et al. 2012). However, the efficacy of alogliptin alone and in combination with pioglitazone to delay the onset of type 2 diabetes has not been previously assessed. In this study, we report that while pioglitazone and alogliptin both produced metabolic benefits, the addition of alogliptin at a dose of $20 \mathrm{mg} / \mathrm{kg}$ per day to pioglitazone treatment did not produce a greater delay in diabetes onset than pioglitazone alone. Furthermore, alogliptin did not produce a delay in diabetes onset at this dose on its own. Of note, only one dose of alogliptin was tested in this study. While this dose is similar to or higher than doses of

Published by Bioscientifica Ltd. 

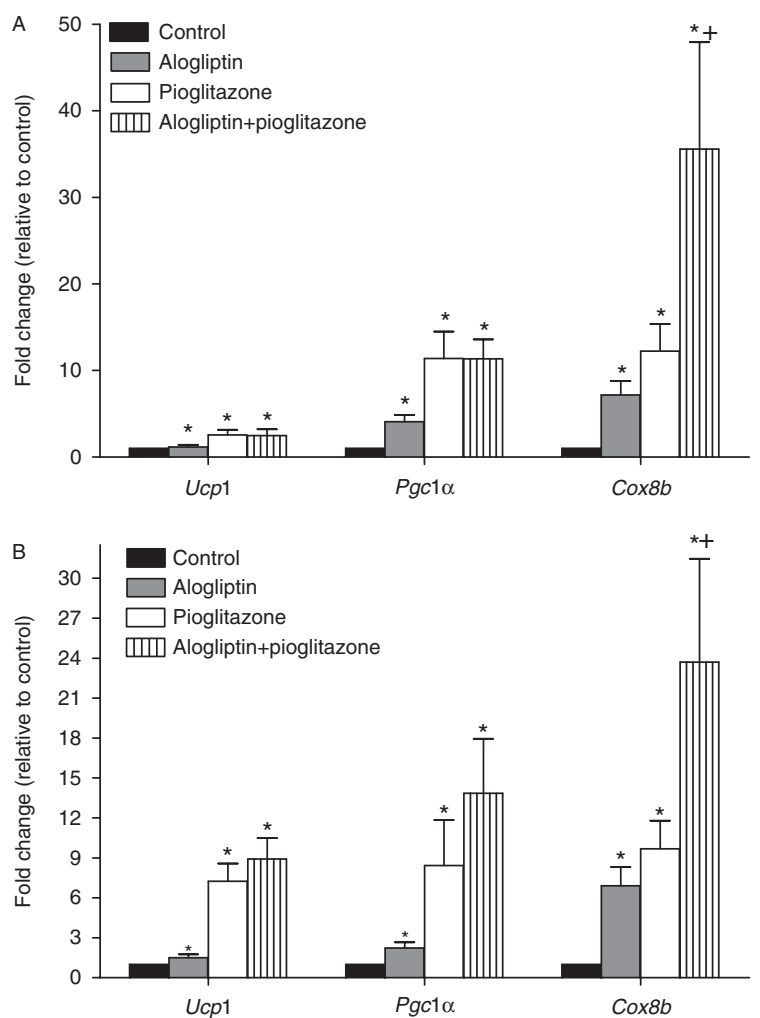

Figure 7

mRNA of Ucp 1, Pgc1 $\alpha$, and Cox8b in subcutaneous BAT (A) and WAT (B), normalized to $\beta$-actin mRNA. ${ }^{*} P<0.05$ compared with control and ${ }^{+} P<0.05$ compared with pioglitazone alone by Student's $t$-test, $n=16$ per group.

alogliptin employed in most previously published rodent studies (Feng et al. 2007, Lee et al. 2008, Asakawa et al. 2009), there is a possibility that the efficacy of alogliptin would have been enhanced at a higher dose. By contrast, pioglitazone alone and in combination with alogliptin delayed type 2 diabetes onset by $\sim 5$ months compared with control UCD-T2DM rats.

The effect of pioglitazone to delay diabetes onset was independent of food intake and BW as both were higher in pioglitazone-treated animals compared with controls. Numerous studies on rodents and humans have reported that TZDs increase BW by increasing adipogenesis, fluid retention, and food intake (Shimizu et al. 1998, Lehrke et al. 2005). Similar to previous studies, alogliptin did not affect food intake or BW (Kawashima et al. 2011, Shah et al. 2011). Increases of adiposity in pioglitazone-treated animals primarily involved the subcutaneous adipose depot and not the mesenteric adipose depot. Previous studies have shown that the effect of TZDs to increase adiposity is primarily restricted to the subcutaneous adipose depot, sparing the more metabolically detrimental visceral depot, allowing for improved insulin sensitivity in the face of increased adiposity (Miyazaki et al. 2002).

Pioglitazone and alogliptin appear to act in an additive manner to improve glucose tolerance and insulin secretion during the OGTT. Furthermore, fasting plasma insulin concentrations were lower and activation of downstream insulin signaling proteins were higher in pioglitazonetreated animals, suggesting that improvements of insulin sensitivity likely contributed to the improvement of glucose tolerance with pioglitazone treatment. The effect of pioglitazone treatment to improve insulin sensitivity has been previously described in both human clinical studies and studies on rodents (Olefsky 2000, Ferre 2004). We hypothesize that the decrease in GLP1 secretion during the OGTT in alogliptin-treated animals is likely due to downregulation of GLP1 secretion over time following repeated increases in postprandial GLP1 secretion.

Islet immunohistochemistry revealed marked improvements of islet morphology in all treatment groups compared with the control group. We hypothesize that $\beta$-cell mass was lower in the groups treated with pioglitazone because these groups were more insulin sensitive resulting in less islet hypertrophy. The improvement of islet morphology in alogliptin-treated animals was surprising in light of alogliptin's lack of effect on diabetes onset. This suggests that the development of type 2 diabetes in the UCD-T2DM rat is, at least initially, more heavily reliant on development of insulin resistance. The effect of alogliptin to reduce pancreatic glucagon content is in line with previous studies reporting that GLP1 signaling results in decreased glucagon secretion from $\alpha$-cells, partially indirectly due to GLP1-induced pancreatic somatostatin secretion (Fehmann \& Habener 1991). The effect of alogliptin to reduce pancreatic glucagon likely contributed to the effect of alogliptin in combination with pioglitazone to reduce circulating glucagon concentrations and represents a metabolic benefit of addition of alogliptin to pioglitazone therapy.

Another potential mechanism by which pioglitazone treatment delayed diabetes onset is by increasing circulating adiponectin concentrations leading to subsequent increases in AMPK activation. Activation of AMPK promotes glucose uptake and lipid oxidation and inhibits glucose and lipid production (Long \& Zierath 2006). We confirmed that pioglitazone treatment increases AMPK activation with corresponding increases in phosphorylation and inactivation of ACC in BAT and subcutaneous WAT. Previous studies have demonstrated that AMPK can inactive ACC resulting in reduced malonyl-CoA concentrations, which enhances the movement of long-chain acyl-CoA into the

Published by Bioscientifica Ltd. 
mitochondria for $\beta$-oxidation (Winder \& Hardie 1996, Winder et al. 1997). These findings suggest that pioglitazone treatment promotes an increase in fatty acid oxidation in adipose tissue, which likely contributed to the decreases in circulating and liver lipid concentrations; however, further studies are needed to confirm these findings. This reduction of hepatic lipid deposition likely contributed to the improvement of insulin sensitivity with pioglitazone treatment as lipid deposition in liver has been shown to inhibit insulin signaling through promotion of serine phosphorylation of insulin receptor substrate proteins (Samuel \& Shulman 2012). Surprisingly, TG deposition was increased in skeletal muscle in pioglitazone-treated animals compared with controls despite improvements of fasting plasma insulin concentrations and glucose tolerance observed with pioglitazone treatment. Interestingly, a previous study on human type 2 diabetic patients reports that treatment with pioglitazone improves insulin sensitivity without altering skeletal muscle TG deposition (Rabol et al. 2010). Furthermore, a previous study in sucrose-fed rats reports an increase in muscle TG deposition with pioglitazone treatment (Markova et al. 2010). By contrast, pioglitazone treatment also appears to enhance fatty acid synthesis as indicated by increased protein expression of FAS in BAT and WAT. This is similar to a previous report on humans and suggests that pioglitazone also reduces hepatic ectopic lipid deposition by diverting lipid into adipose stores (Ranganathan et al. 2006). In line with this finding, studies have shown that increases in de novo lipogenesis in WAT improve insulin sensitivity (Cao et al. 2008, Roberts et al. 2009, Eissing et al. 2013).

Interestingly, alogliptin treatment also resulted in a small but significant elevation of AMPK activation in BAT and subcutaneous WAT and inactivation of ACC in BAT. However, alogliptin treatment did not produce decreases in circulating lipid concentrations or ectopic lipid deposition, similar to what has been reported in previous clinical studies (Bosi et al. 2011). This suggests that these modest elevations of AMPK activity are not sufficient to lower circulating lipids or ectopic lipid deposition.

Increases in markers of mitochondrial biogenesis in WAT and BAT may have also contributed to the delay in diabetes onset in pioglitazone-treated animals. BAT is highly thermogenic leading to the loss of energy as heat and subsequent BW loss. Recent reports have revealed that WAT has the capacity to express a BAT-like phenotype under certain conditions such as cold exposure, $\beta$-adrenergic stimulation, and PPAR $\gamma$ agonism (Kajimura et al. 2010). Results from previous studies indicate that $\operatorname{PPAR} \gamma$ agonists can enhance the thermogenic activity of
BAT and can induce a WAT-to-BAT conversion by activating PPAR $\gamma$ and PPAR response elements on the promoter and/or enhancer region of brown adipose genes (Sears et al. 1996, Ohno et al. 2012). Increased markers of mitochondrial biogenesis in BAT and WAT with pioglitazone treatment corresponded with increased markers of $\beta$-oxidation. Previous studies have reported that pioglitazone does not increase energy expenditure despite its effects on mitochondrial biogenesis but that it does increase the capacity for sympathetically mediated energy expenditure in rodents (Sell et al. 2004). However, increases in mitochondrial biogenesis may have also contributed to the improvements of lipid metabolism with pioglitazone treatment by favoring the use of lipids for energy through $\beta$-oxidation.

Interestingly, alogliptin-treated animals also exhibited increases in markers of mitochondrial biogenesis compared with control animals, although these increases were less dramatic than those observed in pioglitazonetreated animals. These results are similar to those from a previous report that another DDP-IV inhibitor, des-fluorositagliptin, increases mRNA expression of UCP1 and PGC1 $\alpha$ in BAT (Shimasaki et al. 2013).

In conclusion, we have demonstrated that pioglitazone markedly delays the onset of type 2 diabetes in the UCDT2DM rat and that this delay in onset is not enhanced by co-administration with alogliptin. Alogliptin treatment at a dose of $20 \mathrm{mg} / \mathrm{kg}$ per day resulted in modest improvements of glucose tolerance, glucose-stimulated insulin secretion, islet morphology, and markers of mitochondrial biogenesis. While alogliptin is effective in the management of type 2 diabetic patients (Bosi et al. 2011, DeFronzo et al. 2012), the metabolic improvements observed with alogliptin treatment in prediabetic UCD-T2DM rats do not appear to be sufficiently robust to result in a delay in diabetes onset alone or in combination with pioglitazone.

\section{Supplementary data}

This is linked to the online version of the paper at http://dx.doi.org/10.1530/ JOE-13-0601.

\section{Declaration of interest}

The authors have no conflicts to disclose except that $\mathrm{P} J \mathrm{H}$ received funding from Takeda Pharmaceuticals USA, Inc. to perform this project.

\section{Funding}

This research was supported by a grant from Takeda Pharmaceuticals USA, Inc. This research was partly supported by NIH grant numbers

Published by Bioscientifica Ltd 
RC1DK087307 and R01DK095960 to B P C and P J H and RO1DK090492 to $\mathrm{F} \mathrm{G} \mathrm{H}$. Dr Havel's laboratory also received funding during the project period from NIH grant numbers R01HL091333 and R01HL107256 and a Multicampus Award from the University of California, Office of the President.

\section{Acknowledgements}

The authors thank Ashley Loureiro, Ruby Hsieh, Alison Huynh, Michelle Flores, Roel Vink, Joseph Zoline-Black, Vincent Lee, and Lauren Colby for their extensive help with animal care, monitoring, and data collection. They also thank Sue Bennet and Cheryl Phillips and the Meyer Hall Animal Facility for excellent animal care. They thank Linda Jung, Steven Wagner, and MSD for the use of the Sector Imager 2400. They would also like to thank the Center for Comparative Medicine at UC Davis for assistance with preparation of tissues for immunohistochemistry.

\section{References}

Asakawa T, Moritoh Y, Kataoka O, Suzuki N, Takeuchi K \& Odaka H 2009 A novel dipeptidyl peptidase-4 inhibitor, alogliptin (SYR-322), is effective in diabetic rats with sulfonylurea-induced secondary failure. Life Sciences 85 122-126. (doi:10.1016/j.lfs.2009.04.024)

Baggio LL \& Drucker DJ 2007 Biology of incretins: GLP-1 and GIP. Gastroenterology 132 2131-2157. (doi:10.1053/j.gastro.2007.03.054)

Bosi E, Ellis GC, Wilson CA \& Fleck PR 2011 Alogliptin as a third oral antidiabetic drug in patients with type 2 diabetes and inadequate glycaemic control on metformin and pioglitazone: a 52-week, randomized, double-blind, active-controlled, parallel-group study. Diabetes, Obesity \& Metabolism 13 1088-1096. (doi:10.1111/ j.1463-1326.2011.01463.x)

Brubaker PL \& Drucker DJ 2004 Minireview: Glucagon-like peptides regulate cell proliferation and apoptosis in the pancreas, gut, and central nervous system. Endocrinology 145 2653-2659. (doi:10.1210/ en.2004-0015)

Cao H, Gerhold K, Mayers JR, Wiest MM, Watkins SM \& Hotamisligil GS 2008 Identification of a lipokine, a lipid hormone linking adipose tissue to systemic metabolism. Cell 134 933-944. (doi:10.1016/j.cell.2008.07.048)

Cardoso AR, Queliconi BB \& Kowaltowski AJ 2010 Mitochondrial ion transport pathways: role in metabolic diseases. Biochimica et Biophysica Acta 1797 832-838. (doi:10.1016/j.bbabio.2009.12.017)

Cummings BP, Digitale EK, Stanhope KL, Graham JL, Baskin DG, Reed BJ, Sweet IR, Griffen SC \& Havel PJ 2008 Development and characterization of a novel rat model of type 2 diabetes mellitus: the UC Davis type 2 diabetes mellitus UCD-T2DM rat. American Journal of Physiology. Regulatory, Integrative and Comparative Physiology 295 R1782-R1793. (doi:10.1152/ajpregu.90635.2008)

Cummings BP, Stanhope KL, Graham JL, Baskin DG, Griffen SC, Nilsson C, Sams A, Knudsen LB, Raun K \& Havel PJ 2010 Chronic administration of the glucagon-like peptide- 1 analog, liraglutide, delays the onset of diabetes and lowers triglycerides in UCD-T2DM rats. Diabetes 59 2653-2661. (doi:10.2337/db09-1564)

Czyzyk A \& Szczepanik Z 2000 Diabetes mellitus and cancer. European Journal of Internal Medicine 11 245-252. (doi:10.1016/S09536205(00)00106-0)

Danaei G, Finucane MM, Lu Y, Singh GM, Cowan MJ, Paciorek CJ, Lin JK, Farzadfar F, Khang YH, Stevens GA et al. 2011 National, regional, and global trends in fasting plasma glucose and diabetes prevalence since 1980: systematic analysis of health examination surveys and epidemiological studies with 370 country-years and 2.7 million participants. Lancet 378 31-40. (doi:10.1016/S0140-6736(11)60679-X)

DeFronzo RA \& Abdul-Ghani MA 2011 Preservation of $\{\beta\}$-cell function: the key to diabetes prevention. Journal of Clinical Endocrinology and Metabolism 96 2354-2366. (doi:10.1210/jc.2011-0246)
DeFronzo RA, Fleck PR, Wilson CA \& Mekki Q 2008 Efficacy and safety of the dipeptidyl peptidase- 4 inhibitor alogliptin in patients with type 2 diabetes and inadequate glycemic control: a randomized, double-blind, placebo-controlled study. Diabetes Care 31 2315-2317. (doi:10.2337/ dc08-1035)

DeFronzo RA, Tripathy D, Schwenke DC, Banerji M, Bray GA, Buchanan TA, Clement SC, Henry RR, Hodis HN, Kitabchi AE et al. 2011 Pioglitazone for diabetes prevention in impaired glucose tolerance. New England Journal of Medicine 364 1104-1115. (doi:10.1056/NEJMoa1010949)

DeFronzo RA, Burant CF, Fleck P, Wilson C, Mekki Q \& Pratley RE 2012 Efficacy and tolerability of the DPP-4 inhibitor alogliptin combined with pioglitazone, in metformin-treated patients with type 2 diabetes. Journal of Clinical Endocrinology and Metabolism 97 1615-1622. (doi:10.1210/jc.2011-2243)

Drucker DJ \& Nauck MA 2006 The incretin system: glucagon-like peptide-1 receptor agonists and dipeptidyl peptidase-4 inhibitors in type 2 diabetes. Lancet 368 1696-1705. (doi:10.1016/S0140-6736(06)69705-5)

Eliasson B, Moller-Goede D, Eeg-Olofsson K, Wilson C, Cederholm J, Fleck P, Diamant M, Taskinen MR \& Smith U 2012 Lowering of postprandial lipids in individuals with type 2 diabetes treated with alogliptin and/or pioglitazone: a randomised double-blind placebo-controlled study. Diabetologia 55 915-925. (doi:10.1007/ s00125-011-2447-3)

Eissing L, Scherer T, Todter K, Knippschild U, Greve JW, Buurman WA, Pinnschmidt HO, Rensen SS, Wolf AM, Bartelt A et al. 2013 De novo lipogenesis in human fat and liver is linked to ChREBP- $\beta$ and metabolic health. Nature Communications 4 1528. (doi:10.1038/ncomms2537)

Fehmann HC \& Habener JF 1991 Functional receptors for the insulinotropic hormone glucagon-like peptide-I(7-37) on a somatostatin secreting cell line. FEBS Letters 279 335-340. (doi:10.1016/0014-5793(91)80182-3)

Feng J, Zhang Z, Wallace MB, Stafford JA, Kaldor SW, Kassel DB, Navre M, Shi L, Skene RJ, Asakawa T et al. 2007 Discovery of alogliptin: a potent, selective, bioavailable, and efficacious inhibitor of dipeptidyl peptidase IV. Journal of Medicinal Chemistry 50 2297-2300. (doi:10.1021/jm070104l)

Ferre P 2004 The biology of peroxisome proliferator-activated receptors: relationship with lipid metabolism and insulin sensitivity. Diabetes 53(Suppl 1) S43-S50. (doi:10.2337/diabetes.53.2007.S43)

Kajimura S, Seale P \& Spiegelman BM 2010 Transcriptional control of brown fat development. Cell Metabolism 11 257-262. (doi:10.1016/ j.cmet.2010.03.005)

Kaku K, Itayasu T, Hiroi S, Hirayama M \& Seino Y 2011 Efficacy and safety of alogliptin added to pioglitazone in Japanese patients with type 2 diabetes: a randomized, double-blind, placebo-controlled trial with an open-label long-term extension study. Diabetes, Obesity \& Metabolism 13 1028-1035. (doi:10.1111/j.1463-1326.2011.01460.x)

Kawashima S, Matsuoka TA, Kaneto H, Tochino Y, Kato K, Yamamoto K, Yamamoto T, Matsuhisa M \& Shimomura I 2011 Effect of alogliptin, pioglitazone and glargine on pancreatic $\beta$-cells in diabetic $\mathrm{db} / \mathrm{db}$ mice. Biochemical and Biophysical Research Communications 404 534-540. (doi:10.1016/j.bbrc.2010.12.021)

Kim HI \& Ahn YH 2004 Role of peroxisome proliferator-activated receptor- $\gamma$ in the glucose-sensing apparatus of liver and $\beta$-cells. Diabetes 53(Suppl 1) S60-S65. (doi:10.2337/diabetes.53.2007.S60)

Lee B, Shi L, Kassel DB, Asakawa T, Takeuchi K \& Christopher RJ 2008 Pharmacokinetic, pharmacodynamic, and efficacy profiles of alogliptin, a novel inhibitor of dipeptidyl peptidase-4, in rats, dogs, and monkeys. European Journal of Pharmacology 589 306-314. (doi:10.1016/ j.ejphar.2008.04.047)

Lehrke M, Pascual G, Glass CK \& Lazar MA 2005 Gaining weight: the Keystone Symposium on PPAR and LXR. Genes and Development 19 1737-1742. (doi:10.1101/gad.1341005)

Long YC \& Zierath JR 2006 AMP-activated protein kinase signaling in metabolic regulation. Journal of Clinical Investigation 116 1776-1783. (doi:10.1172/JCI29044)

Markova I, Zidek V, Musilova A, Simakova M, Mlejnek P, Kazdova L \& Pravenec M 2010 Long-term pioglitazone treatment augments insulin

Published by Bioscientifica Ltd. 
sensitivity and PKC-epsilon and PKC-theta activation in skeletal muscles in sucrose fed rats. Physiological Research 59 509-516.

Mazzone T, Chait A \& Plutzky J 2008 Cardiovascular disease risk in type 2 diabetes mellitus: insights from mechanistic studies. Lancet $\mathbf{3 7 1}$ 1800-1809. (doi:10.1016/S0140-6736(08)60768-0)

Miyazaki Y, Mahankali A, Matsuda M, Mahankali S, Hardies J, Cusi K, Mandarino LJ \& DeFronzo RA 2002 Effect of pioglitazone on abdominal fat distribution and insulin sensitivity in type 2 diabetic patients. Journal of Clinical Endocrinology and Metabolism 87 2784-2791. (doi:10.1210/jcem.87.6.8567)

Moritoh Y, Takeuchi K, Asakawa T, Kataoka O \& Odaka H 2008 Chronic administration of alogliptin, a novel, potent, and highly selective dipeptidyl peptidase- 4 inhibitor, improves glycemic control and $\beta$-cell function in obese diabetic ob/ob mice. European Journal of Pharmacology 588 325-332. (doi:10.1016/j.ejphar.2008.04.018)

Moritoh Y, Takeuchi K, Asakawa T, Kataoka O \& Odaka H 2009 The dipeptidyl peptidase-4 inhibitor alogliptin in combination with pioglitazone improves glycemic control, lipid profiles, and increases pancreatic insulin content in ob/ob mice. European Journal of Pharmacology 602 448-454. (doi:10.1016/j.ejphar.2008.11.017)

Nissen SE, Nicholls SJ, Wolski K, Nesto R, Kupfer S, Perez A, Jure H, De Larochelliere R, Staniloae CS, Mavromatis K et al. 2008 Comparison of pioglitazone vs glimepiride on progression of coronary atherosclerosis in patients with type 2 diabetes: the PERISCOPE randomized controlled trial. Journal of the American Medical Association 299 1561-1573. (doi:10.1001/jama.299.13.1561)

Nolte RT, Wisely GB, Westin S, Cobb JE, Lambert MH, Kurokawa R, Rosenfeld MG, Willson TM, Glass CK \& Milburn MV 1998 Ligand binding and co-activator assembly of the peroxisome proliferatoractivated receptor- $\gamma$. Nature 395 137-143. (doi:10.1038/25931)

Ohno H, Shinoda K, Spiegelman BM \& Kajimura S 2012 PPAR $\gamma$ agonists induce a white-to-brown fat conversion through stabilization of PRDM16 protein. Cell Metabolism 15 395-404. (doi:10.1016/j.cmet.2012.01.019)

Olefsky JM 2000 Treatment of insulin resistance with peroxisome proliferator-activated receptor $\gamma$ agonists. Journal of Clinical Investigation 106 467-472. (doi:10.1172/JCI10843)

Pratley RE, Kipnes MS, Fleck PR, Wilson C \& Mekki Q 2009a Efficacy and safety of the dipeptidyl peptidase- 4 inhibitor alogliptin in patients with type 2 diabetes inadequately controlled by glyburide monotherapy. Diabetes, Obesity \& Metabolism 11 167-176. (doi:10.1111/j.1463-1326.2008.01016.x)

Pratley RE, Reusch JE, Fleck PR, Wilson CA \& Mekki Q 2009b Efficacy and safety of the dipeptidyl peptidase- 4 inhibitor alogliptin added to pioglitazone in patients with type 2 diabetes: a randomized, doubleblind, placebo-controlled study. Current Medical Research and Opinion 25 2361-2371. (doi:10.1185/03007990903156111)

Rabol R, Boushel R, Almdal T, Hansen CN, Ploug T, Haugaard SB, Prats C, Madsbad S \& Dela F 2010 Opposite effects of pioglitazone and rosiglitazone on mitochondrial respiration in skeletal muscle of patients with type 2 diabetes. Diabetes, Obesity \& Metabolism 12 806-814. (doi:10.1111/j.1463-1326.2010.01237.x)

Ranganathan G, Unal R, Pokrovskaya I, Yao-Borengasser A, Phanavanh B, Lecka-Czernik B, Rasouli N \& Kern PA 2006 The lipogenic enzymes DGAT1, FAS, and LPL in adipose tissue: effects of obesity, insulin resistance, and TZD treatment. Journal of Lipid Research 47 2444-2450. (doi:10.1194/jlr.M600248-JLR200)

Ritz E, Rychlik I, Locatelli F \& Halimi S 1999 End-stage renal failure in type 2 diabetes: a medical catastrophe of worldwide dimensions. American Journal of Kidney Diseases 34 795-808. (doi:10.1016/ S0272-6386(99)70035-1)

Roberts R, Hodson L, Dennis AL, Neville MJ, Humphreys SM, Harnden KE, Micklem KJ \& Frayn KN 2009 Markers of de novo lipogenesis in adipose tissue: associations with small adipocytes and insulin sensitivity in humans. Diabetologia 52 882-890. (doi:10.1007/s00125-009-1300-4)
Rosen ED \& Spiegelman BM 2001 PPAR $\gamma$ : a nuclear regulator of metabolism, differentiation, and cell growth. Journal of Biological Chemistry 276 37731-37734. (doi:10.1074/jbc.M106424200)

Rosenstock J, Rendell MS, Gross JL, Fleck PR, Wilson CA \& Mekki Q 2009 Alogliptin added to insulin therapy in patients with type 2 diabetes reduces $\mathrm{HbA}(1 \mathrm{C})$ without causing weight gain or increased hypoglycaemia. Diabetes, Obesity \& Metabolism 11 1145-1152. (doi:10.1111/ j.1463-1326.2009.01124.x)

Rosenstock J, Inzucchi SE, Seufert J, Fleck PR, Wilson CA \& Mekki Q 2010 Initial combination therapy with alogliptin and pioglitazone in drugnaive patients with type 2 diabetes. Diabetes Care 33 2406-2408. (doi:10.2337/dc10-0159)

Samuel VT \& Shulman GI 2012 Mechanisms for insulin resistance: common threads and missing links. Cell 148 852-871. (doi:10.1016/ j.cell.2012.02.017)

Sears IB, MacGinnitie MA, Kovacs LG \& Graves RA 1996 Differentiationdependent expression of the brown adipocyte uncoupling protein gene: regulation by peroxisome proliferator-activated receptor $\gamma$. Molecular and Cellular Biology 16 3410-3419.

Sell H, Berger JP, Samson P, Castriota G, Lalonde J, Deshaies Y \& Richard D 2004 Peroxisome proliferator-activated receptor $\gamma$ agonism increases the capacity for sympathetically mediated thermogenesis in lean and ob/ob mice. Endocrinology 145 3925-3934. (doi:10.1210/en.2004-0321)

Semple RK, Chatterjee VK \& O'Rahilly S 2006 PPAR $\gamma$ and human metabolic disease. Journal of Clinical Investigation 116 581-589. (doi:10.1172/ JCI28003)

Shah Z, Kampfrath T, Deiuliis JA, Zhong J, Pineda C, Ying Z, Xu X, Lu B, Moffatt-Bruce S, Durairaj R et al. 2011 Long-term dipeptidyl-peptidase 4 inhibition reduces atherosclerosis and inflammation via effects on monocyte recruitment and chemotaxis. Circulation 124 2338-2349. (doi:10.1161/CIRCULATIONAHA.111.041418)

Sharma AM \& Staels B 2007 Review: Peroxisome proliferator-activated receptor $\gamma$ and adipose tissue - understanding obesity-related changes in regulation of lipid and glucose metabolism. Journal of Clinical Endocrinology and Metabolism 92 386-395. (doi:10.1210/jc.2006-1268)

Shimasaki T, Masaki T, Mitsutomi K, Ueno D, Gotoh K, Chiba S, Kakuma T \& Yoshimatsu H 2013 The dipeptidyl peptidase-4 inhibitor des-fluorositagliptin regulates brown adipose tissue uncoupling protein levels in mice with diet-induced obesity. PLOS ONE 8 e63626. (doi:10.1371/ journal.pone.0063626)

Shimizu H, Tsuchiya T, Sato N, Shimomura Y, Kobayashi I \& Mori M 1998 Troglitazone reduces plasma leptin concentration but increases hunger in NIDDM patients. Diabetes Care 21 1470-1474. (doi:10.2337/diacare. 21.9.1470)

Thomas L, Eckhardt M, Langkopf E, Tadayyon M, Himmelsbach F \& Mark M 2008 (R)-8-(3-amino-piperidin-1-yl)-7-but-2-ynyl-3-methyl1-(4-methyl-quinazolin-2-ylm ethyl)-3,7-dihydro-purine-2,6-dione (BI 1356), a novel xanthine-based dipeptidyl peptidase 4 inhibitor, has a superior potency and longer duration of action compared with other dipeptidyl peptidase-4 inhibitors. Journal of Phamacology and Experimental Therapeutics 325 175-182. (doi:10.1124/jpet.107.135723)

Winder WW \& Hardie DG 1996 Inactivation of acetyl-CoA carboxylase and activation of AMP-activated protein kinase in muscle during exercise. American Journal of Physiology 270 E299-E304.

Winder WW, Wilson HA, Hardie DG, Rasmussen BB, Hutber CA, Call GB, Clayton RD, Conley LM, Yoon S \& Zhou B 1997 Phosphorylation of rat muscle acetyl-CoA carboxylase by AMP-activated protein kinase and protein kinase A. Journal of Applied Physiology 82 219-225. (doi:10.1063/ 1.365801)

Zhang X, Wang Z, Huang Y \& Wang J 2011 Effects of chronic administration of alogliptin on the development of diabetes and $\beta$-cell function in high fat diet/streptozotocin diabetic mice. Diabetes, Obesity \& Metabolism 13 337-347. (doi:10.1111/j.1463-1326.2010.01354.x)

Received in final form 30 January 2014

Accepted 3 February 2014 http://joe.endocrinology-journals.org DOI: 10.1530/JOE-13-0601
(C) 2014 Society for Endocrinology Printed in Great Britain 